(1)

CrossMark

\title{
“Lung sparing growth": is the lung not affected by malnutrition?
}

\author{
Insa Korten ${ }^{1,2,3}$, Jakob Usemann ${ }^{1,3}$ and Philipp Latzin ${ }^{1}$
}

Affiliations: ${ }^{1}$ Pediatric Respiratory Medicine, Dept of Pediatrics, Inselspital, Bern University Hospital, University of Bern, Bern, Switzerland. ${ }^{2}$ Graduate School for Cellular and Biomedical Sciences, University of Bern, Bern, Switzerland. ${ }^{3}$ University Children's Hospital Basel (UKBB), Basel, Switzerland.

Correspondence: Philipp Latzin, Division of Respiratory Medicine, Dept of Pediatrics, Inselspital, University of Bern, Freiburgstrasse 31, 3010 Bern, Switzerland. E-mail: philipp.latzindinsel.ch

@ERSpublications

"Lung sparing growth": intriguing hypothesis to explain why the lung is not affected by severe acute malnutrition http://ow.ly/9V5d309M1ho

Cite this article as: Korten I, Usemann J, Latzin P. "Lung sparing growth": is the lung not affected by malnutrition? Eur Respir J 2017; 49: 1700295 [https://doi.org/10.1183/13993003.00295-2017].

Malnutrition is a major cause of mortality and morbidity in developing countries [1]. It has been reported to play a role in different acute and chronic disease conditions [2-4], including respiratory diseases and lung development $[5,6]$. Starting in utero, maternal malnutrition during pregnancy may influence postnatal lung function directly (e.g. through decreased alveolar number), or indirectly (e.g. through intrauterine growth retardation, prematurity or low birth weight) [7]. There is clear evidence of detrimental effects of vitamin A deficiency in pregnancy on lung function in childhood [8]. Early postnatal malnutrition was associated with several adverse pulmonary effects and lung injury in animal models, e.g. decreased lung protein and DNA synthesis in the lungs [9], whereas breastfeeding and balanced nutrition is thought to be protective $[10,11]$. Furthermore, Vitamin D and C deficiency have been reported to cause deficits in lung function and structure [12, 13]. To summarise, malnutrition potentially influences respiratory health and lung function on multiple levels.

In this regard, the study reported by LeLIJVELD et al. [14] in this issue of the European Respiratory Journal is surprising, as they report that severe acute malnutrition (SAM) in childhood does not have negative effects upon later lung function. The authors investigated the effect of SAM on spirometry outcomes 7 years later in young Malawian children from a prospective cohort study, within a case-control design. Cases were children between the ages of 7 and 15 years, admitted to a nutrition ward 7 years earlier for treatment of SAM. Notably, the authors selected two different control groups: 1) siblings not treated for SAM and 2) community controls, matched for sex and age. High quality spirometry measurements were assessed in 237 children in the case group, and in 143 (in the first group) and 121 (second group) children, respectively, from the two control groups. The authors reported that all measured spirometry values were slightly lower than expected from standard reference values (Global Lung Function Initiative z-scores; e.g. mean forced expiratory volume in $1 \mathrm{~s}$ z-score: -0.47 for cases; -0.48 for siblings; -0.34 for community controls) [15]. However, they did not find clear differences in lung function parameters between the three groups. What they did observe was a preservation of sitting height, while leg length was shorter in SAM survivors compared to both control groups. Furthermore, in the whole sample, as well as within the case group, girls and HIV positive children had lower lung function parameters [14].

While the authors have previously published the overall results, along with other adverse long-term effects of SAM [16], in the current article they describe in more detail results on lung function measurements.

Received: Feb 102017 | Accepted after revision: March 032017

Conflict of interest: Disclosures can be found alongside this article at erj.ersjournals.com

Copyright CERS 2017 
All spirometry measurements were performed at one centre by three trained data collectors, assuring data quality. An additional strength of this study is the large number of demographic factors collected, as well as the history of respiratory symptoms, HIV and tuberculosis status and information about the home environment. As this allows high methodological quality, given the knowledge about malnutrition and lung growth as outlined above, it seems especially surprising that no significant differences in lung function data across the three groups were observed.

The authors hypothesise that this could be due to "thrifty" or "lung sparing growth", which is supported in this study by compromised leg length in the case group. Although highly speculative, this seems to be an intriguing theory. A pattern of shorter legs, but preserved torso height, might allow lung function to be preserved. This pattern of preserved organ function has been already described for the brain ("brain sparing growth") [17]. The authors could not show clear associations between specific height measurements (e.g. adjustment for sitting height or leg length) and lung function data. However, the slightly reduced leg length compared to the preserved sitting height leads the authors to conclude that there may be a "lung sparing growth" effect of SAM. This would need to be evaluated in future studies, and separately for different nutritional components, such as vitamins [8].

Some additional factors have to be considered when interpreting these findings. As acknowledged by the authors, $46 \%$ of the case group died before follow up. Thus, it is likely that the more severe SAM cases, which presumably had poorer lung function outcomes, could not be measured in the study. In addition, they report rather reduced values of all spirometry parameters in the cases and control groups. This could hint towards an overall poorer nutrition status in all groups, which could hamper the ability to observe an effect of malnutrition on lung function in the case group.

Besides actual nutrition status, pre- and early postnatal history might also be of relevance. However, data on nutrition intake and environmental exposure during pregnancy, gestational age, precise birth weight, as well as breastfeeding status were not known; all factors known to clearly influence early lung growth [18]. Not being able to control for these could have biased the results. For example, exposure to malnutrition during pregnancy for both case and control groups could lead via lower birth weight to overall lower lung growth in all groups. The sample size needed to show an effect in the exposure group could be too small in the current study without considering this. It could also be possible that, by chance, the number of children with additional (pre- or postnatal) risk factors for an impaired lung function is overrepresented in the control groups, which would potentially mask an effect of SAM on lung growth during childhood.

Moreover, the exact period during which SAM occurred might be especially important. It is known that alveolarisation continues at least until the age of 2 years [19] and that susceptibility of lung development toward external influences depends on age [20]. Therefore, the malnutrition status previous to SAM diagnosis, which was not assessed in this study, could differently impact lung development. The authors divided the case group into two groups of children younger and older than 2 years of age, and did not find differences in outcomes. A more detailed analysis of age at SAM occurrence, however, might have revealed vulnerable time periods.

As spirometry measures large airways, and less well overall lung volume or peripheral airways, other lung function measurements might be more sensitive to discover early effects of SAM. Although more elaborate, expensive and time consuming measurements, parameters obtained from body plethysmography (e.g. total lung capacity), or washout measurements (e.g. functional residual capacity and lung clearance indices) [21], could be valuable for future studies.

All these points reveal how difficult it is to identify associations of SAM and lung growth as an interplay of several different factors contributing to lung development. In this regard, the study design was excellent and the authors tried to disentangle the complex interactions of early and acute effects, environmental factors and diseases; especially considering the challenging study setting in Malawi. Overall, it seems possible that in future studies a more detailed investigation of age and type of malnutrition (e.g. vitamin deficiency) might lead to further knowledge regarding the exact effects of malnutrition on lung growth and the intriguing hypothesis of "lung sparing growth". This would foster greater understanding of early treatment and post discharge care of malnutrition to reduce long-term adverse outcomes, which is of utmost importance from a public health perspective.

\section{References}

$1 \quad$ UNICEF. Levels and Trends in Child Mortality: Report 2011. New York, United Nations Children's Fund, 2011.

2 Deribew A, Tessema GA, Deribe K, et al. Trends, causes, and risk factors of mortality among children under 5 in Ethiopia, 1990-2013: findings from the Global Burden of Disease Study 2013. Popul Health Metr 2016; 14: 42.

3 Makdad AM, Forouzanfar MH, Daoud F, et al. Health in times of uncertainty in the eastern Mediterranean region, 1990-2013: a systematic analysis for the Global Burden of Disease Study 2013. Lancet Glob Health 2016; 4: e704-e713. 
4 Schofield C, Ashworth A. Why have mortality rates for severe malnutrition remained so high? Bull World Health Organ 1996; 74: 223-229.

5 Karim T, Muhit M, Khandaker G. Interventions to prevent respiratory diseases - Nutrition and the developing world. Paediatr Respir Rev 2016; in press [https://doi.org/10.1016/j.prrv.2016.09.003].

6 Stocks J, Hislop A, Sonnappa S. Early lung development: lifelong effect on respiratory health and disease Lancet Respir Med 2013; 1: 728-742.

7 Pike K, Jane Pillow J, Lucas JS. Long term respiratory consequences of intrauterine growth restriction. Semin Fetal Neonatal Med 2012; 17: 92-98.

8 Checkley W, West KPJ, Wise RA, et al. Maternal vitamin A supplementation and lung function in offspring. N Engl J Med 2010; 362: 1784-1794

9 Bhatia J, Parish A. Nutrition and the lung. Neonatology 2009; 95: 362-367.

10 Frey U, Latzin P, Usemann J, et al. Asthma and obesity in children: current evidence and potential systems biology approaches. Allergy 2015; 70: 26-40.

11 Soto-Ramirez N, Alexander M, Karmaus W, et al. Breastfeeding is associated with increased lung function at 18 years of age: a cohort study. Eur Respir J 2012; 39: 985-991.

12 Grievink L, Smit HA, Ocké MC, et al. Dietary intake of antioxidant (pro)-vitamins, respiratory symptoms and pulmonary function: the MORGEN study. Thorax 1998; 53: 166-171.

13 Zosky GR, Berry LJ, Elliot JG, et al. Vitamin D deficiency causes deficits in lung function and alters lung structure. Am J Respir Crit Care Med 2011; 183: 1336-1343.

14 Lelijveld N, Kerac M, Seal A, et al. Long-term effects of severe acute malnutrition on lung function in Malawian children: a cohort study. Eur Respir J 2017; 49: 1601301.

15 Quanjer PH, Stanojevic S, Cole TJ, et al. Multi-ethnic reference values for spirometry for the 3-95-yr age range: the global lung function 2012 equations. Eur Respir J 2012; 40: 1324-1343.

16 Lelijveld N, Seal A, Wells JC, et al. Chronic disease outcomes after severe acute malnutrition in Malawian children (ChroSAM): a cohort study. Lancet Glob Health 2016; 4: e654-e662.

17 Wells JC. The thrifty phenotype: An adaptation in growth or metabolism? Am J Hum Biol 2011; 23: 65-75.

18 Korten I, Ramsey K, Latzin P. Air pollution during pregnancy and lung development in the child. Paediatr Respir Rev 2017; 21: 38-46.

19 Kajekar R. Environmental factors and developmental outcomes in the lung. Pharmacol Ther 2007; 114: 129-145.

20 Postma DS, Bush A, van den Berge M. Risk factors and early origins of chronic obstructive pulmonary disease. The Lancet 2015; 385: 899-909.

21 Yammine S, Schmidt A, Sutter O, et al. Functional evidence for continued alveolarisation in former preterms at school age? Eur Respir J 2016; 47: 147-155. 